\title{
En marcha un estudio sobre los procesos de patrimonialización de la cultura de frontera en el sur ibérico
}

\begin{abstract}
Se denomina Patrimonio Cultural y Memoria de fronteras en el Sur Ibérico y es un proyecto liderado por el grupo de investigación out_arquías, con componentes de las universidades de Pablo de Olavide y de Sevilla. Comenzó a ejecutarse a principios de 2020 y tiene prevista una duración de tres años. La investigación se centra en los procesos de patrimonialización de la frontera que se dan en los municipios limítrofes andaluces con el Alentejo portugués en la actualidad, atendiendo al papel relevante que adquiere el patrimonio inmaterial al mismo tiempo que advierte sobre el riesgo de una excesiva banalización en su puesta en valor.
\end{abstract}

Elodia Hernández León | Dpto. de Antropología Social, Psicología Básica y Salud Pública, Universidad Pablo de Olavide

URL de la contribución <http://www.iaph.es/revistaph/index.php/revistaph/article/view/5064>

Las fronteras políticas interestatales son espacios emblemáticos para el análisis de los proyectos nacionales de los estados europeos ${ }^{1}$. Lugares donde las distintas dimensiones socioeconómicas y simbólicas se dan con la tensión del encuentro entre dos órdenes separados por las barreras que dibujan los límites, pero que no logran interrumpir del todo la proximidad, la continuidad de los territorios. La presencia cotidiana del otro Estado nación hace de las áreas fronterizas espacios de especial relevancia para el estudio del patrimonio cultural en su relación con la constitución de las identidades nacionales.

Siendo así, el proceso de integración de la Unión Europea, con la consecuente apertura de las fronteras interiores, afectará a las áreas fronterizas de especial forma al promocionar la inclusión de los vecinos de otros estado en una misma entidad supranacional.

A partir de los años noventa, con el impulso de los fondos europeos de Interreg, asistimos a una generalizada emergencia de proyectos de puesta en valor de los patrimonios culturales de la frontera para el desarrollo de unas zonas ubicadas en las periféricas socioeconómicas de los estados. Y en esta emergencia, paulatinamente, irán ganando peso los patrimonios que visibilizan la frontera, aquellos patrimonios que no son otros que los derivados del hecho fronterizo.
Conocedoras de los patrimonios inmateriales tradicionales del tramo andaluz de la frontera luso-española (Hernández León et ál. 1999) y ante la observación de las transformaciones en las activaciones patrimoniales del área, diseñamos un proyecto para su abordaje. Partimos de la superación de las nociones tradicionales del patrimonio cultural para enfocarnos en el estudio de los procesos de patrimonialización; indagando en la selección de aspectos y agentes que intervienen y, en definitiva, teniendo en cuenta, mas allá del tratamiento del patrimonio como objeto de consumo para el visitante, las memorias compartidas entre las poblaciones fronterizas que permanecieron ocultas en las historias oficiales cuyas narrativas redundaban en un secular darse la espalda (Hernández León y Castaño Madroñal 1996, 150) de los estados lusos e hispanos. Esto es lograr entender unos procesos de patrimonialización en los que se revaloriza la frontera desde la aproximación a la cultura de frontera (Hernández León y Castaño Madroñal 1992) de las poblaciones limítrofes andaluzas-alentejanas.

El proyecto de I+D+I Patrimonio Cultural y Memorias de Frontera en el Sur Ibérico se presentó a la convocatoria de ayudas en concurrencia competitiva a proyectos de $I+D+i$ en el marco del Programa Operativo FEDER Andalucía 2014-2020 en el 2018 y tras un periodo de evaluación en la DEVA (Dirección de Evaluación y Acreditación de la Agencia Andaluza del Conocimiento), 


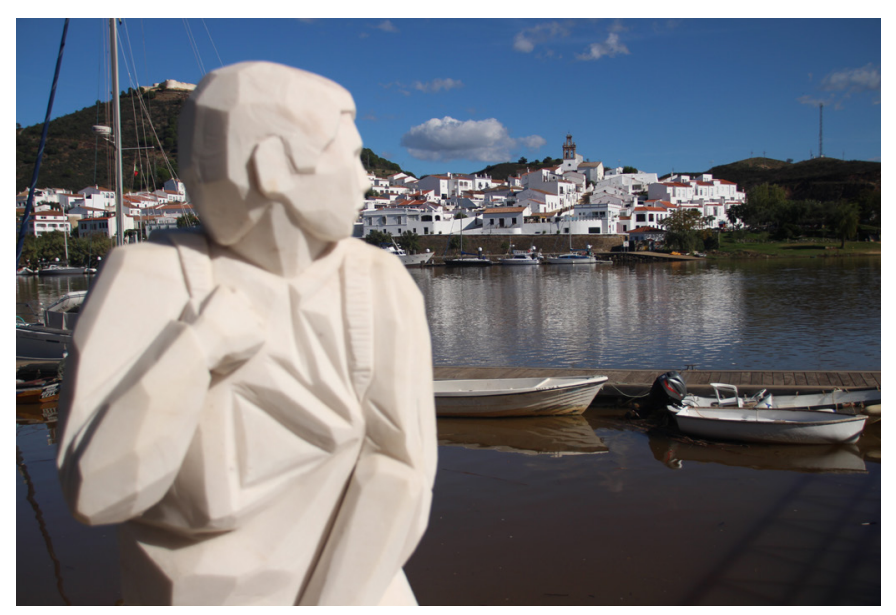

Estatua de contrabandista de Alcoutim (Portugal); al fondo, Sanlúcar de Guadiana | foto Fondo del proyecto (Belén Maldonado)

que resultó positiva, comienza a ejecutarse en enero del 2020 con una estimación de dos años y uno más de prórroga, dada las limitaciones de las medidas sanitarias del periodo de incidencia de la COVID-19.

Dicho proyecto fue impulsado por el grupo de investigación out_arquías ${ }^{2}$ al que pertenecen su investigadora principal, Elodia Hernández, de la Universidad Pablo de Olavide, y Juan Agudo Torrico, Ángeles Castaño, Carmen Guerra, María Prieto y Assumpta Sabuco, de la Universidad de Sevilla. También cuenta con un equipo de colaboración en el que, además de otros miembros de out_arquias (Jorge Minget, Mariano Pérez y Carolina Prieto), está implicado el Instituto Andaluz del Patrimonio Histórico, a través de la participación de María Carmen Rodríguez, junto a Dèsiderio Batista, de la Universidad del Algarve, y Rute Sousa, de la Universidad de Évora.

Con una metodología de perspectiva cualitativa, la investigación, tomando en cuenta el contexto global, se aproxima a los procesos de patrimonialización de la frontera desde las definiciones y narrativas locales de emergencias de estos patrimonios internacionales. La selección de los casos tomó el criterio de inclusión de las localidades ubicadas en el límite, aquellas que habían sido aduanas o pasos tradicionales por dibujar la frontera con las líneas de sus propias demarcaciones municipales: nuestra observación directa, participación y entrevistas se desarrollan en los municipios onubenses de
Encinasola, Rosal de la Frontera, Paymogo, El Granado y Sanlúcar del Guadiana.

La ejecución de este proyecto además fluye con la intencionalidad o el convencimiento de la necesaria imbricación con los agentes de patrimonialización local y en general, con las narrativas y memorias de los grupos sociales que han permanecido en la sombra. Esta finalidad tuvo la realización de las jornadas con nombre Valoración y Dinamización del Patrimonio Cultural Transfronterizo celebradas el pasado mes de octubre en Encinasola, en uno de los recursos municipales paradigmáticos de la puesta en valor de este patrimonio, nos referimos al Aula de la Naturaleza, antigua casa de carabineros ubicada en la Contienda, en una encrucijada de caminos del contrabando.

En estas jornadas se pusieron en evidencia las claves de los procesos de patrimonialización que se están dando entre las poblaciones cofronterizas y que apuntan a una emergencia de las relaciones vecinales entre poblaciones a ambos lados de la línea fronteriza. Contactos sociales que nunca se interrumpieron, a pesar de la solidificación de las fronteras en los periodos más represivos de nuestra historia. En esos momentos el desarrollo del comercio ilícito y su continuidad en la

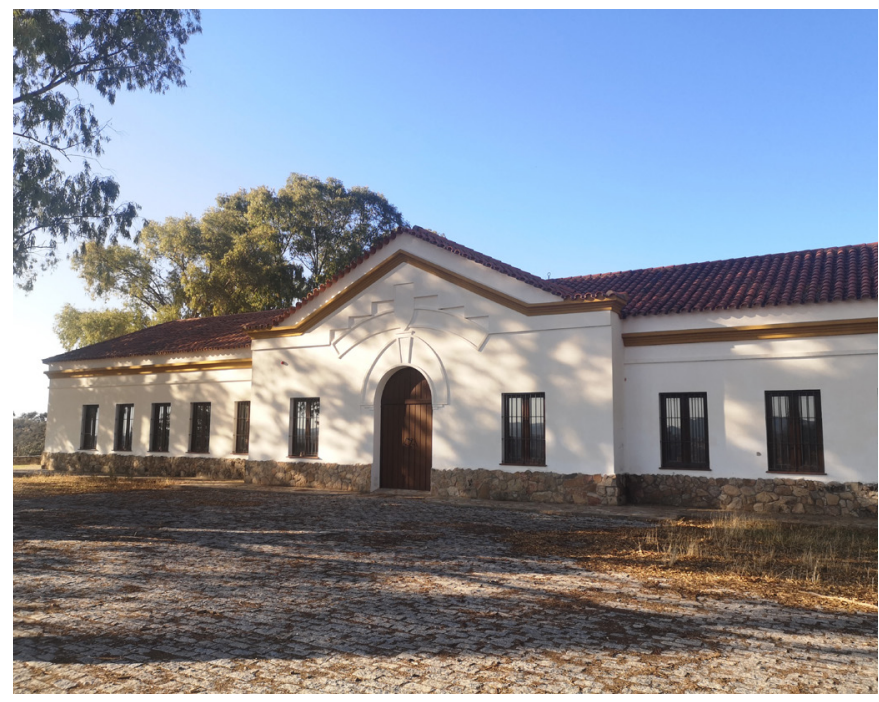

Casa de Carabineros próxima a la línea fronteriza (actual Aula de la Naturaleza) | foto Fondo del proyecto (Juan Agudo) 


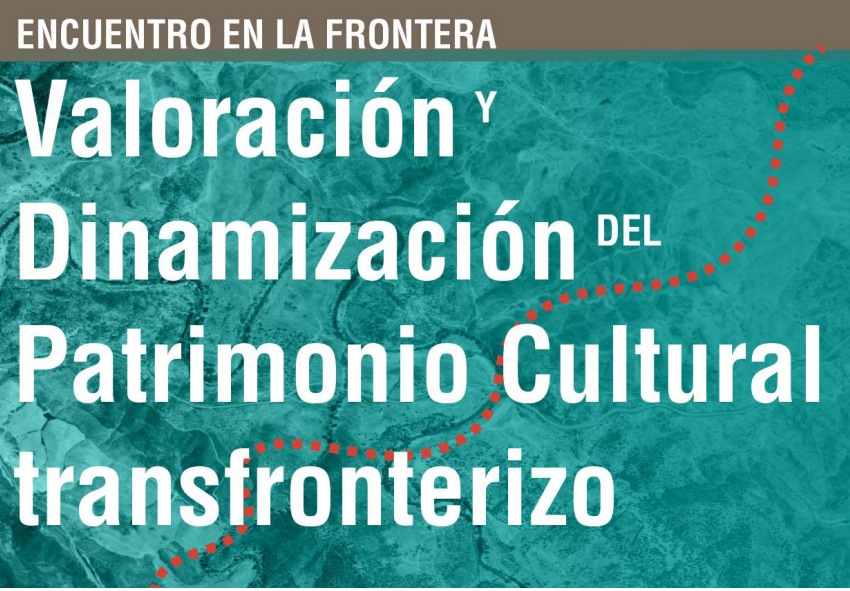

Banner del workshop del proyecto | diseño Fondo del Proyecto (BPSALDISEÑO)

trama de relaciones interfronterizas supone un verdadero desafío al muro estatal, un muro que siempre fue permeable y redefinido en función de los intereses y lecturas locales (Hernández León y Castaño Madroñal 1992, 2018).

También se evidencia la necesidad de tener en cuenta los patrimonios inmateriales que ocupan un lugar central en estos procesos de patrimonialización puesto que son actividades socioeconómicas, como el comercio o los aprovechamientos mineros o los agropecuarios, a través de las cuales emerge esa cultura de frontera. Junto a la centralidad de aquellos, también es necesario entender a los patrimonios monumentales, como fortalezas, baluartes y castillos, antes los únicos emblemáticos del patrimonio de frontera, desde nuevas lecturas a partir de las definiciones cotidianas y locales de la frontera.

Finalmente se constata que la patrimonialización de la frontera, en el contexto de la integración de las regiones europeas, supone una oportunidad para las poblaciones sometidas históricamente a la condición limítrofe y periférica, una oportunidad de dinamización socioeconómica de éxito relativo, pero sin duda una oportunidad para activar en el área el capital simbólico de una historia compartida y singular y de visibilizarse de cara a sus propios centros. Aunque también implica un riesgo por la excesiva banalización en los procesos de mercantilización de los patrimonios transfronterizos.
Nuestro proyecto de investigación continuará ahondando en estas cuestiones y contribuyendo a los procesos de patrimonialización locales promoviendo próximas citas y encuentros internacionales en la frontera política y del conocimiento.

\section{NOTAS}

1. Esta contribución se ha realizado en el marco del proyecto de investigación de referencia FEDER UPO1263940 Patrimonio cultural y memorias de frontera en el Sur Ibérico cuya IP es Elodia Hernández y ha sido cofinanciada por Fondo Europeo de Desarrollo Regional (FEDER) y por la Consejería de Economía, Conocimiento, Empresas y Universidad de la Junta de Andalucía. En el marco del programa operativo FEDER Andalucía 2014-2020. Objetivo específico 1.2.3.Fomento y generación de conocimiento frontera orientado a los retos de la sociedad, desarrollo de tecnologías emergentes.

2. El grupo out_arquías es un grupo PAl registrado en la Junta de Andalucía (HUM-853).

\section{BIBLIOGRAFÍA}

- Hernández León, E. y Castaño Madroñal, A. (1996) Una frontera, un espacio social cambiante: la Raya de Portugal. Demófilo, Revista de Cultura Tradicional de Andalucía. Sevilla: Fundación Machado, pp. 139-154

- Hernández León, E. y Castaño Madroñal, A. (2018) La patrimonialización de los paisajes transfronterizos. En: Prieto Peinado M. (ed.) Valoración y regeneración del paisaje transfronterizo. Seminario de investigación Out_arquias 2018. Málaga: RU Books-Recolectores urbanos, pp. 92-101

- Hernández León, E. y Castaño Madroñal, A. (1992) Expresiones simbólicas y cultura de frontera en La Raya de Portugal (Provincia de Huelva). En: Anuario Etnológico de Andalucía 1991. Sevilla: Consejería de Cultura de la Junta de Andalucía, pp. 123-126

- Hernández León, E., Castaño Madroñal, A., Quintero Morón, V. y Cáceres Feria, R. (1999) Fiesta y frontera: transformaciones de las expresiones simbólicas en la franja fronteriza de Huelva. Sevilla: Consejería de Cultura, Junta de Andalucía 